\title{
The Man from Somewhere: Author, Affiliation, and Letterhead
}

\author{
Patricia Mooney Nickel
}

\section{| Introduction}

This is not an essay composed for the Telos competition; it is an essay about the Telos competition. I addresses "no specific question or theme" other than the request for the author's institutional affiliation, a form of symbolic capital that, for much of his career, the founder of Telos could not have produced. The seemingly open invitation to participate in the Telos essay competition masks a union of author and affiliation that functions powerfully as it shapes academic careers according to the quest for the knowledge authority embedded in institutional letterhead and directs creative energies into the collection of status displays, while knowledge continues to be legitimated according to its institutional origination. I argue that the value relations within which the potential Telos author is embedded belong to what Michel Foucault described as the "author function." I explore these value relations through a consideration of the ways in which manners, money, and letterhead circulate through academic status displays, which preserve an economy of affiliation that portrays the personal consequences of status disqualification as matters of merit, when they are in fact matters of governing the boundaries of legitimate knowledge.

\section{From the Author Function to the Affiliation Function}

The requirement that one be affiliated with an institution in order to enter the Telos essay competition suggests that the author must produce an affiliation in order to be known as an author at all. Affiliation as a criterion of recognition indicates that the status of "author" is achieved on the basis of factors other than the composition of a text (authoring). In order to understand this identification of the author in the institutional context of academic life, I revisit Michel Foucault's inquiry into how some texts come to be acknowledged as authored, while others do not. Foucault (1998) raises the question, what is the function, or the usefulness, of the title "author" in relationship to present social relations and the management of meaning and legitimate knowledge? For Foucault (1998) the “author's name manifests the appearance of a certain discursive set and indicates the status of this discourse within a society and a culture... The author function is therefore characteristic of the mode of existence, circulation, and functioning of certain discourses in society" (211). From this perspective, the author's name designates not only a person, but also a particular discourse within which some individuals are able to achieve authoritative status through the production of texts, which become objects of appropriation subject to value relations (Foucault 1998: 211212). In academic discourse today, the same is true of affiliation, which performs the role of distinguishing which academic authors are worthy of recognition/valorization and, as a result, governs the circulation of knowledge. In its present constitution of author status, the affiliation function legitimizes a particular discourse and allows for the institutional extraction of value from those individuals who "author" it.

As a basis for categorizing and valorizing "legitimate knowledge," the author function can be extended to the role of affiliation in academic literary practices positioned within the institutional framework of the university. As Joseph R. Urgo (1999) notes: 
"Traditionally, affiliation fixed paternity through adoption or the legal connection of an illegitimate child to its father. Today the term is institutional, not familial, but its roots are nonetheless in assigning origins to someone, something more than employment, something closer to identity... affiliation listed in print below one's name is a mark not so much of destination or residency but of origin and legitimacy" (18-19).

While the title "author" provides a basis for the categorization of texts (Foucault 1998: 210), titles achieved through affiliation provide the basis for the categorization of those who produce them.

Employed as a qualification, affiliation acts as an efficient means of governing the boundaries of knowledge according to its institutional origination. If the author function characterized the relationship between individual, text, and the circulation of meaning, the affiliation function subverts this relationship by first qualifying (and thus identifying) the text in relationship with an institution and subsequently appropriating the author as a conduit for the institutional legitimation of knowledge. This legitimacy by origination suggests, as Russell Jacoby (2000) explains:

"that the author of the book passed the test, gaining the approval of a specific network, which filtered out the unkempt and unacceptable. It is a notice of a serious and reputable work. It serves to reassure as well as intimidate readers and reviewers. Even with the requisite qualifier - the opinions and mistakes are strictly the author's - who wants to challenge a book inspected by scores of scholars, published by a major university, and supported by several foundations?" (233).

Affiliation takes over as the source of authority for a text; the legitimacy of the text originates in the institution with which the author is affiliated. The reader enters into an implicitly affirmative relationship with the legitimacy of the institution as the institution stands in as a characteristic of the author, who, in turn, legitimates the institution as a place from which legitimate knowledge originates. The legitimacy of institutions depends upon the author as a vessel for their value and the author depends upon the institution for the status of author. Even if one agrees with Roland Barthes (1977) that to politicize the text "the birth of the reader must be at the cost of the death of the Author," the life of the author cannot be understood outside of the affiliation function, which must preserve the author in order to preserve the privilege of affiliation upon which the power of the relationship between institutions, knowledge, and governing depends.

We can examine the author function as it manifests in the academic profession in order to uncover how it is specifically related to the production of legitimate knowledge within an institutional framework that includes not only universities, but the publication outlets, professional associations, non-profits, foundations, and government organizations that participate in the relations of power/knowledge. In his argument for the "genre function" Anis Bawarshi (2000) notes that we "need a concept that can account not only for how certain 'privileged' discourses function, but also for how all discourses function, an overarching concept that can explain the social roles we assign to various discourses and those who enact and are enacted by them. Genre is such a concept" (338). Bawarshi (2000) is concerned with how to account for that speech that does not achieve author status and thus author-value: "Because we are conceptually limited by the author-function to dismiss nonprivileged (that is, nonliterary) discourse as 'everyday speech that merely comes and goes,' we do not know how to value it' (339). Bawarshi (2000) recognizes genre as a literary institution and seems to propose the genre function as a potential alternative to the author function. This proposal has interesting potential, especially in its extension to academic disciplinary boundaries. I agree with Bawarshi (2000) that the author function may be positioned within the genre function: "it is quite possible that the author-function is itself a function of literary genres, which create the ideological conditions that give rise to this subject we call 'author" (338). However, while Bawarshi (2000) wants to understand the author privilege as a function of genre, for the purposes of this essay I want to understand the author privilege as a function of affiliation.

Building on Bawarshi's (2000) line of reasoning, I argue that, like genre, affiliation constitutes discourses' and writers' "modes of existence, circulation, and functioning within a society." If the author function explains that we assign value and legitimacy to texts according to the title "author," the affiliation function explains that we assign value and legitimacy to the author according to institutional affiliation, which already belongs to an ensemble of knowledge (Foucault 1980). The function of affiliation is to mark the boundaries of legitimate knowledge and legitimate stances towards knowledge as they are embodied in the author. Affiliation privilege as the basis for authorvalue can thus be positioned within Foucault's broader oeuvre, specifically his concern with the value relations of power/knowledge. Indeed, Foucault's (1980) understanding of power/knowledge may already represent an argument for the affiliation function. Through Foucault's lens it can be argued that when institutional affiliation constructs the author, it also constructs our sense of the origination of legitimate knowledge; affiliation governs the boundaries of legitimate knowledge production as it governs who is allowed to participate in its production. Discourse is authored by individuals who are "authored" by affiliation with institutions. These affiliations function to marginalize 
those discourses that are not legitimized by an institutional positioning within what Foucault (1980) recognized as "discursive regimes" involving power effects "peculiar to the play of statements." Institutions participate in these regimes as they sanction knowledge according to "rules of formation" belonging to the ensemble of practices that govern knowledge production:

"It is a question of what governs statements, and the way in which they govern each other so as to constitute a set of propositions which are scientifically acceptable, and hence capable of being falsified by scientific procedures. In short, there is a problem of the regime, the politics of the scientific statement. At this level it's not so much a matter of knowing what external power imposes itself on science, as of what effects of power circulate among scientific statements, what constitutes, as it were, their internal regime of power, and how and why certain moments of that regime undergoes a global modification" (Foucault 1980: 112-113).

The affiliation function contributes to the stability of these knowledge regimes and governs statements as it constitutes the authors of knowledge statements according "rules of formation" that include an institutional subjectivity predisposed to the present.

The author function demonstrates how the status requirements associated with the title "author" influence the quest to become an author, which today must involve the quest for affiliation. Like the status of author cannot be achieved today without affiliation, Foucault (1998) observed that the status of author could not be achieved anonymously: an "anonymous text posted on a wall probably has an editor - but not an author" (211). Certainly, one could write without affiliation, but to do so within the value relations of the academic career is akin to writing anonymously. There is no shortage of venues for "graduate students and post-graduate researchers to tell the world about their work"; in today's crowded corridor of self-publication, against which the author function guards, one not only can read about the work of graduate students and post-graduate researchers, but also the intimate minutia that accompanies it: taking a break from the diss. to walk the dog; need more beer if I am going to finish ch 2; watching American Idol while reading Adorno; celebrating finishing draft of ch on culture with chocolate. One can readily tell the world about their workings and their work; what the Telos essay competition offers is an opportunity for graduate students and post-graduate researchers to be recognized as authors; to have their work celebrated, endorsed, distinguished, and further affiliated; it offers an opportunity to enter into a relation of value. For the purposes of the Telos competition, the unaffiliated writer is anonymous in the sense that she cannot be identified as an author; she is a cipher in the sense that she cannot be valued or contribute value. Affiliation anonymity (independent scholarship) thus becomes productive as it governs who is, and who is not, able to achieve valued authorship: what is legitimately said to be knowledge is governed by who is allowed to say it, which is governed by the "fit" between an author and an institution. Thus, the affiliation function attempts to secure the borders of "legitimate knowledge" against the undisciplined circulation of unauthorized texts.

\title{
Money, Manners, and the Achievement of Letterhead
}

\author{
For one kind of passport - \\ smiling lips part \\ For others - \\ an attitude scornful. \\ — Vladimir Mayakovsky, My Soviet Passport
}

To request an author's affiliation is a powerful act: for one affiliation "smiling lips part," for others, "an attitude scornful." It is therefore troubling that the modern academy cannot determine how to interact with an author without first identifying their affiliation, which is most basically the achievement of access to letterhead. Letterhead, a symbol of one's affiliation, conveys much more than one's address; it affords a form of stylized power to those who possess it. Like the "extent of the power of money is the extent of my power..." (Marx 1978: 103), the extent of the power of one's institutional affiliation is the extent of the power that one has to participate in knowledge production. When affiliation circulates like money through the currency of letterhead, "what I am and am capable of is by no means determined by my individuality" (Marx 1978: 103). When publication depends upon affiliation, "one no longer dares to appear as he is..." as official university letterhead ensures that "one will never know well those with whom he deals..." (Rousseau 1964: 38). 
Indication of one's institutional affiliation is also the donning of attire and just as "richness of attire may announce a wealthy man, and elegance a man of taste," (Rousseau 1964: 37) institutional affiliation may announce a scholar's work as being worthy of recognition. The "greater the prestige of the university with which a scholar is associated, the greater the readiness to credit his work..." (Gouldner, 1970, 201). While "money is the supreme good, therefore its possessor is good," in the academic marketplace, institutional affiliation is the supreme good and therefore its possessor is good; affiliation "is the real mind of all things and how then should its possessor be stupid?” (Marx 1978: 103). As Alvin W. Gouldner (1970) observed:

"Harvard's social position tends to have a 'halo effect' on the prestige of its faculty members. Commonly, that is, the higher the national repute of a university, the higher the prestige of those associated with it. Simply by virtue of being at Harvard a man gets a substantial measure of 'unearned prestige.' A university's prestige, of course, affects the bargaining position of its faculty... [referring] to the treatment of his work in its intellectual market" (200).

A scholar may be "bad, dishonest, unscrupulous, stupid," but their institutional affiliation may be "honoured, and therefore so is its possessor" (Marx 1978: 103). The prestige of the institution, as well as the rank that one has achieved within its structure, stands in for merit. As Stanley Fish (1989) notes: "There will always be those whose words are meritorious (that is, important, worth listening to, authoritative, illuminating) simply by virtue of the position they occupy in the institution... merit is inseparable from the structure of the profession and therefore the fact that someone occupies a certain position in that structure cannot be irrelevant to the assessment of what he or she produces" (167).

The institutional halo effect in an intellectual status market where letterhead may announce a scholar of manners and merit prompts the question: what role can the requirement to declare an institutional affiliation as a preface to one's work play in the judgment of an individual's essay? Surely the absence of institutional affiliation in the Telos essay competition would not inhibit the author's "creative, fresh, and original contributions in the area of politics, philosophy, critical theory, theology, culture, and the arts." On the contrary, reading is distorted by the affiliation preface (an authoring of the author), which, like manners and money, is a filtering lens that blurs the distinction between the text and the value relations that precede the opportunity to circulate it; we are told the accepted value of the text prior to engaging it.

Although, letterhead belongs to a circuitry of valued prestige, which, like money, can stand in for one's personal qualities, the pursuit of affiliation also is the pursuit of what Max Weber called status honor, which cannot be obtained through the possession of money alone. Status privileges, for Weber (1975), result from distinct manners of lifestyle, which are produced and protected by the status group. "[S]tatus honor is normally expressed by the fact that above all else, a specific style of life is expected from all those who wish to belong to the circle" (Weber 1975: 187). Affiliation encourages conformity to the norms associated with particular knowledge regimes and carries with it the burden to project the lifestyle/knowledge according to which a particular institution achieves value. Lifestyle indicators such as education, costume, residence, and disposition - like the dividends of private high school tuition, crimson regalia, the ability to blend in at Cambridge coffee houses, and cool philanthropic accents - are earned at the discretion of the status group, rather than exchanged through the medium of money. Not everyone who possesses money necessarily possesses or can achieve status. In the academic status order, style and knowledge are conflated as affiliation; inclusion in the academic status order is realized through adherence to a particular style of life, which is achieved as one accumulates a particular stance towards knowledge. Affiliation becomes a knowledge lifestyle that functions to legitimate a particular regime of knowledge -- one of the primary tools of governing.

Academic status and the variations in power that accompany it are relayed through one's institutional affiliation, which conveys to the judges of "creative, fresh, and original contributions" that one ascribes to the "definite intellectual form" that "universities encourage" (Jacoby 2000, 232). As Pierre Bourdieu (1984b) notes:

\footnotetext{
"There is no acknowledged master who does not recognize a master and, through him, the intellectual magistrate of the sacred college of masters who acknowledge him. In short, there is no master who does not recognize the value of the institution and its institutional values which are all rooted in the institutionalized refusal of any non-institutionalized thought, in the exaltation of academic 'reliability', that instrument of normalization which has all appearances on its side, those of learning and those of morality, although it is often only the instrument of the transformation of individual and collective limits into the choice of scientific virtuousness" (95, my emphasis).
}

Thought is institutionalized through programs, which institutionalize the programmed and de-institutionalize the non-programmed. (See McGurl 2009 on the Program Era.) That the Telos essay competition is "open to MA and $\mathrm{PhD}$ students as well as post-graduate researchers who are affiliated with an internationally recognized higher 
education institution" and submissions "should indicate the author's institutional affiliation," only contributes to the "institutionalized refusal of any non-institutionalized thought."

The affiliated are the refined; they emerge from program-based canons that have shaped their view of the appropriate boundaries of knowledge organized into disciplines. Bourdieu's (1984a, b) investigations into the accumulation of symbolic, and, more specifically, academic capital demonstrate how the boundaries of academic status groups are maintained as a "reputation for academic worthiness" (96) through rituals that not only distinguish individuals, but also the institutions that provide the "social conditions of the full exercise of philosophical activity" (93). Bourdieu (1984b) observes that academic power is achieved through the transfer of reputation from "heads to clients," or from supervisor/committee chair to Ph.D. student (91). The author affiliated with an unknown university and an unknown dissertation advisor provokes a different editorial reaction than does the legacy of the editor of an important journal or the possessor of Ivy League letterhead.

In its succinct representation of status and academic capital, letterhead provides an efficient means to govern knowledge boundaries. The judgment of individual essays composed along the entire spectrum of human thought and lifestyle would require constant adjustment of one's sense of the boundaries that govern legitimate knowledge. The transaction costs involved in organic interaction with individuals refined with a set of governing tools that differ from one's own are huge: wide variations in origination structure writing style, language, canon, ontological and epistemological assumptions, as well as one's investment in the present and therefore one's willingness to challenge existing thought. In their request for institutional affiliation, the panel of judges for the Telos essay competition has bypassed the judgment of these variations in meaning altogether and outsourced the preliminary screening of the entrants to standardized tests and the admissions offices of the authors' undergraduate institution, which have substantial influence in the trajectory of academic careers. Urgo (1999) recounts how when completing his undergraduate admissions application he listed his father's occupation as machinist and job title as "Joe," which "resulted in my application being discussed around the office and probably contributed more than anything in it to my acceptance. This is a story about class... the pedigree produced by one's education becomes a part of one's identity that is more indelible than one's name" (14).

In excluding the unaffiliated, the Telos competition excludes those who have not successfully conformed to a valorized way of relating to the world. With every request for documentation of origination, one is reminded of their class status and their value in the intellectual market place. Signs of affiliation are embedded in more than the author's name and letterhead. Every entrant may be equal up until the point that their institutional affiliation is announced, but once one reveals their affiliation, one risks revealing a basis for dismissal. To require that an author announce their affiliation is also to require that an author indicate how much power they may potentially exercise over those who judge their work, leaving some feeling powerless. Those with very little academic capital hesitate before writing a scathing review of even poorly written work that emerges from a status order to which they aspire. The author need not explicitly assert her right to privileged consideration of the power she posses by virtue of her relations; she need only demonstrate affiliation with a privileged status group. As Luke (1999) notes: "In the argot of the profession, these disciplinary appraisals are folded into a series of nominative judgments about the power, size, recognition or circulation of authorial presence, or, more colloquially, 'name.' Is one 'a name' to be reckoned with?” (358).

The rituals of academia help "to generate all sorts of acts of obligatory recognition and homage (among which, servile references and reviews are only the most visible) through the effects of authority operated by any legitimate institution, and through the conscious or unconscious deference paid to those people who wield power over coveted positions” (Bourdieu 1984b: 104). The attempts to extract value from one's affiliations, or to achieve more valuable affiliations, "hardly encourage heretical breaks with the artfully intertwined knowledge and power of academic orthodoxy" (Bourdieu 1984b: 105). Faced with these power relations, graduate students are encouraged to calculate maximum return on their investment. As Bourdieu (1984b) explains, "We cannot entirely understand the phenomena of the concentration of academic power without also taking into consideration the contribution made by the claimants, by way of the strategies which lead them towards the most powerful protectors" (91).

The identification of powerful protectors and the most highly-valued affiliation is facilitated by rankings. As Luke (1999) observed, “the ranking system of professional correctness that assays 'where' one's work is done also defines 'how' rewards are or are not allocated, 'when' promotions do or do not occur, 'why' status rises or falls, 'who' wins or loses" (350). The Political Theory and Public Law Job Market Blog (2011) for "prospective grad students in political theory/philosophy to ask questions about different programs, different specializations, and anything else that might come to mind" is dominated by concern with these "arithmetical economies of professional correctness" (Luke 1999: 350). 


\begin{abstract}
Anonymous said...
9:11, see the advice given above - you are not asking the right question. You should be asking, "I have a specific interest in Scottish Enlightenment - which top 10 program should I go to?" Start with the criteria of a strong general education in political theory and a program with a good placement record. Unless you can afford to invest 7 years of your life for a degree that does not lead to a job, do not even think about a program that does not have a strong placement record. That doesn't mean one star student who happened to land a great job -- they need to have a consistent record of placing students, year in and year out. That narrows you down to the top 10 programs. Then you can select which of those programs might have someone who could supervise a dissertation on the Scottish Enlightenment. Maybe apply to one or two other borderline programs with strength in your area. Georgetown might make your list at the very bottom, but you should be thinking primarily about programs like Harvard, Princeton, and Chicago.
\end{abstract}

11:00 AM, July 19, 2009

\title{
Anonymous said...
}

The signal that you're being sent by being admitted to a top program is that some pretty smart \& experienced people think you have a shot. (This, by the way, is another reason why attending a "top" program is important; since the opposite signal is being sent if you *don't* get admitted to one of those programs. It's an imperfect signal, obviously, but a signal nonetheless)...

12:48 PM, July 20, 2009

The potential Ph.D. student is well-advised, if not for their personal esteem and creative expression, for a career in an academy in which affiliation dominates authorship. Top-ten letterhead will serve her well if she hopes to enter the Telos competition, and also if she hopes to present a paper at the American Political Science Association conference, which in 2008 required applicants to indicate where they earned their Ph.D. when submitting a proposal. In the crowd of authors attempting to demonstrate their merit, letterhead becomes the most efficient way to convey one's status in order to instigate what public administration scholars call "bureaucratic discretion." As Timothy W. Luke (1999) notes: "Without any other stable measure of value, the systems of continuous normalizing judgment typically use obvious indicators of status, like institutional location or professional position, to measure worth" (350). These status indicators relayed through affiliation transfer a series of judgments made prior to the judgment of the author's actual essay, ensuring that an essay produced by an unaffiliated author is not declared legitimate or valuable; knowledge of an author's affiliation simultaneously protects its judge from the risk of alienating an author's powerful "protectors" who protect the status of those whose names they have invested in.

With so many invested in the truth-value of these ranking regimes (Luke 1999: 350), the success of lower-ranked winners causes distress for higher-ranked losers.

Anonymous said...

Va Tech hired Chad Lavin (Penn State PhD)

11:19 AM, April 01, 2008

\section{Anonymous said...}

Re: 8:19--either that is a hilarious April Fool's Joke, or the idea that pedigree matters is thrown right out the window. I have no idea who Chad Lavin is, and I am sure he is an excellent political theorist; that is not the funny part. Nor am I discounting the quality of those theorists left at Penn State, that is not what is making me laugh either. Just noticing the irony of a candidate from a school that wants to rid itself of theory producing a candidate who lands a really good job. So much for the letter from the Foundations people. That said, if this is true and not an April Fool's joke, congratulations to Lavin and I wish you the best of luck.

2:52 PM, April 01, 2008

\section{Anonymous said...}

not really...a Penn State PhD going to V Tech makes sense... its not like a VT PhD going to Princeton or Chicago.

3:05 PM, April 01, 2008

(Political Theory and Public Law Job Market Blog, 2011). 
The idea that Lavin could have value independent of his Ph.D. affiliation is so discomforting that it is said to be the equivalent of an April fool's joke. Anonymous 2:52 PM vents a thinly-veiled contempt for those who transgress prestige-based entitlements: "the idea that pedigree matters is thrown right out the window." Rather than challenging the politics of pedigree, in his or her response, Anonymous 2:52 PM argues not that pedigree is a poor indicator of value, but that Penn State and Virginia Tech are of the same value in the institutional market place, yet still of less value than Princeton or Chicago. Anonymous 2:52 PM and Anonymous 3:05 PM seem troubled by their apparent miscalculation of the weight of reputation in the "economic calculus of the academic career" (Agger 1990). Individuals do occasionally transcend their station, often because powerful committees and editors, of which Telos founder Paul Piccone was one, take it upon themselves to disrupt this status order. Someone interacted with and valued Lavin as an individual; someone did not trust institutional affiliation as an indicator of value. The unease that is unleashed by this disruption of the status order is a discomfort with the fact that Lavin's hire betrays the idea that one's affiliation status is an indicator of one's merit: it devalues affiliation and in doing so challenges those whom Luke (1999) identified as "academic political scientists [who] clutch their journal placements, publishing houses, editorial posts, citation counts, granting agencies, and department affiliations as the tangible markers of predestined significance and well-deserved success" (356).

To directly challenge Lavin's merit independent of his affiliation would also challenge the value of affiliation, which relies upon the myth that affiliation is an indicator of merit. Anonymous 2:52 PM is careful to note that, although he has no idea who Chad Lavin is, "I am sure he is an excellent political theorist." Exchanges of affiliation value are unique in that status relies upon one not being able to make a direct trade of money for affiliation. Jean Baudrillard (1981) argued: "In consumption generally, economic exchange value (money) is converted into sign exchange value (prestige, etc.); but this operation is still sustained by the alibi of use value" (112). In academia, the alibi for the sign value of affiliation is merit. As with Weber's understanding of status, the assumption is that, although one may convert money into an education, one cannot only convert money into an education. Those who convert money into an education are also said to have merit, which is achieved through a particular knowledge lifestyle; one cannot exchange money for affiliation without also having a claim merit. However, this is complicated by the fact that affiliation often stands in for merit. Affiliation serves as an alibi for merit and merit as an alibi for affiliation. This reciprocal alibi is reinforced by the occasional film celebrating stories such as a Harvard graduate student falling in love with a brilliant MIT janitor who, in spite of his lifestyle, is embraced by the academy because he solves math problems while mopping the floor on the night shift. The fairytale myth of merit triumphing over lifestyle preserves the status value of affiliation in an "equal opportunity" society.

Widespread belief in the merit alibi is critical to the legitimacy of knowledge regimes and the stability of what Foucault (1980) discussed as a political economy of truth "centered on the form of scientific discourse and the institutions which produce it..." (131). Like status, merit cannot be claimed independent of recognition by the profession. Anonymous 2:52 PM must ascribe merit to Lavin because to do otherwise would be to imply that merit is not the source of pedigreed privilege: prestige relies upon the myth of merit. However, as Fish (1989) notes, merit "rather than being a quality that can be identified independently of professional or institutional conditions, is a product of those conditions; and, moreover, since those conditions are not stable but change continually, the shape of what will be recognized as meritorious is always changing too" (166). Merit, like author and affiliation, is "characteristic of the mode of existence, circulation, and functioning within a society" (211).

In the same way that government imposes a politics-administration dichotomy (Waldo 1948) and positivism imposes a politics-science dichotomy (Agger 1989), academia imposes a politics-merit dichotomy. This claim to inclusiveness by way of apolitical standards of exclusion is what makes the merit alibi so difficult for the outsider to challenge. Merit, as Fish (1989) argues, is rarely defined beyond what it is not: bias. Furthermore, when lower-ranked individuals challenge prestige-based merit this only magnifies the fact that they do not have it and those who do have it point to such challenges as evidence for why one does not deserve it. Terry Caesar (1992), who is a good example of an intellectual with more merit than affiliation prestige, points out how such challenges are "relegated to a species of protest" of a foolish sort (151). Were an entrant to the Telos competition to compose a cover letter like that composed by Caesar (1989) when inquiring into a Woodrow Wilson Fellowship there is little doubt that the judges of its "merit" would wonder whether or not her dissertation chair had reviewed her materials: "To be quite blunt about it: what are the chances of someone who applies from an institution with the above letterhead actually being awarded a fellowship? Just about nil, I'd say. You know it. I know it. Now you know I know it. But you're not going to tell me you know it in a written statement. Fair enough. You will want to tell me instead about pluralistic aims, humanistic goals, fair practices, and so on" (151). The practices that Caesar points to characterize most institutions that engage in governing through grant-making based on "the merit" of proposals. As INCITE! Women of Color 
Against Violence (2007) put it, "the revolution will not be funded."

The politics of merit can be synthesized within the affiliation function in order to uncover how the request for institutional affiliation in the practice of publishing governs knowledge. Academic authors produce knowledge, which achieves value through publication/circulation. The status of academic author is constituted through institutional affiliation. Institutional affiliation carries with it a particular orientation towards the world, rendered in the knowledge lifestyle of the status order. The status order and associated institutionalized thought are transmitted through the refinement of Ph.D. students, who practice these rituals in order to achieve the status of author, without which they cannot participate in academic discourse. Thus, the production of knowledge is governed as status, protected by the merit alibi, becomes the basis for the legitimacy of the text. Within this regime, affiliation represents one's possession of academic capital, indicating not only the power that one possesses, but also the value that can be extracted from the entrant should their essay be chosen for display. At the same time, one accumulates more academic power as one accumulates more publications, which, as the Telos competition indicates, are more readily accumulated by those who possess institutional affiliation.

\section{Collectors and Academic Status Displays}

People who are refined visit other refined people and confide in them, chattering and babbling about precisely what they have experienced and whether they found the experience indigestible or pleasing.

\section{— Robert Walser, Microscript 215}

The quest to extract value from affiliation redirects critical creative energies into the frantic collection and display of academic status portfolios. Making their way through conference hotels and social networking sites, junior academics discuss themselves as designer commodities in the academic marketplace; most will inform others of their institutional affiliation and status adornments within five minutes of meeting them and those with the most highlyranked affiliation leave the least amount of time for a new acquaintance to know them as someone other than whom they are affiliated with. Some forgo their own voice altogether and instead wear their institutional affiliation on their breasts so that the newly made acquaintance knows them prior to their speaking at all: casual sweatshirts emblazoned with university logos announce with a seeming aloofness the formality of one's education. With their affiliation established, they go on to demonstrate their refined taste, voicing their displeasure at discovering that they were at a panel where a "nobody" spoke and the pleasure that they took in hearing a "someone." These displays reveal a fear of being known as oneself prior to being known according to one's institutional affiliation and thus a fear of being deprived the advantages of their status group.

If we understand the art auction as the collection of affiliations and the art lover as a collector, Baudrillard's (1981) analysis of the art lover can be extended to these collectors of academic status:

\footnotetext{
"The singularity that he asserts - that fetishist passion for the object lived as an elective affinity - is established on his recognition as a peer, by virtue of a competitive act, in a community of the privileged. He is the equal of the canvas itself, whose unique value resides in the relation of parity, of statutory privilege, which, as a sign, it maintains with the other terms of the limited corpus of paintings. Hence the 'elitist' affinity between the amateur and the canvas that psychologically connotes the very sort of value, of exchange and of aristocratic social relation that is instituted by the auction. The passion of the amateur is ignited by the latent summation, by the exalting and continual obsession of all other amateurs, just as the fetishized value of the canvas, his mana is made from: its differential reference to all the other canvases in the same sublime sphere of status; its pedigree, its genealogy, that is, its signature and the cycle of its successive owners... (118).
}

The possessor of institutional affiliation imagines himself the equal of the institution itself, valued through the appearance of parity that results from the possession of one of a limited number of positions in a valued collection. As they pursue status through the collection of affiliations that might generate the appearance of parity and obsession of the unaffiliated amateurs, academics convert "knowledge as a universal value into knowledge as a sign value, as a title of nobility, is accompanied by the same legitimation, the same discrimination of the peers who participate in the white mass, in this sacrament." (Baudrillard 1981: 122). Through the collection of affiliations, one transforms their investment in a highly-valued knowledge lifestyle into a status portfolio, as Luke (1999) describes: "the placement of articles and books become the blue book on one's career or the means for assaying the placement of one's labor in departments, between different universities, or within the discipline itself..." (350). 
Signs of affiliation are no longer limited to letterhead, crest-bearing sweatshirts, and conference badges. In the wake of blogs, Twitter, and Facebook, new status markets have emerged in spaces such as Academia.edu -- the "Facebook of academia" -- which distinguishes "academic" chatter as being somehow more refined than that of the general public. While most Americans who benefit from class-based privilege have become sophisticated in the practice of upholding the myth of a "classless society," with its merit alibi the academy still finds it appropriate to outwardly display and celebrate class markers in spaces such as academia.edu, which remains a status-bearing "network" organized by institutional affiliations and hierarchy, with faculty members, post-docs, and graduate students arranged in organizational charts according to their status.

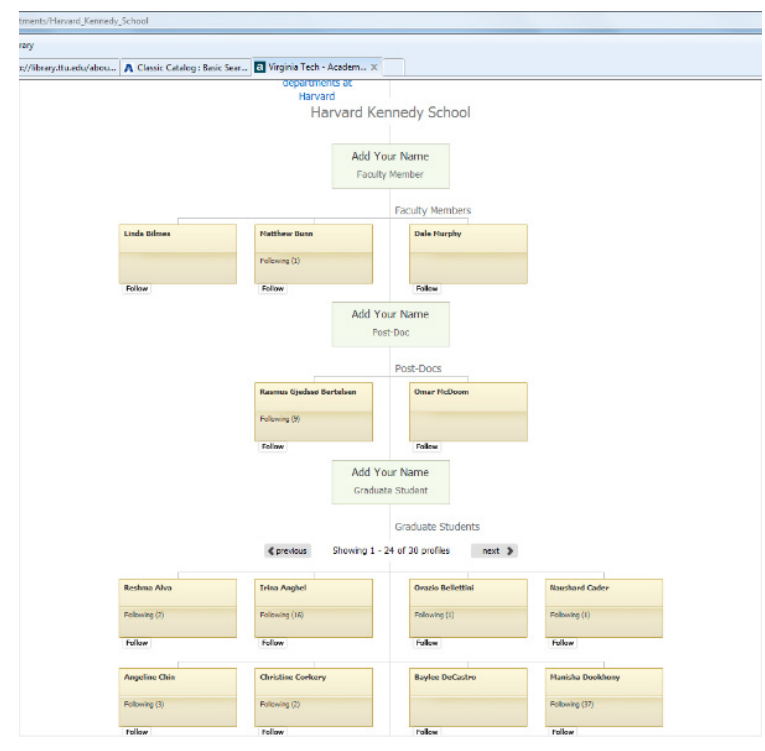

(Academia.edu 2011)

The replication of academic status displays involving affiliation and rank within a networking site should come as no surprise; "space embodies social relationships" (Lefebvre 1991: 26; see Crampton 2003).

While academia.edu promotes itself as a space within which academics can share their work and follow the work of others, as Baudrillard (1981) observed of the academic conference, it entails an exchange of signs that has more to do with value fetishes than it does with the substantive discussion of ideas. As Jeffery Di Leo (2003) observed: "Affiliation with star scholars has become fetishized in academic culture" (2). Di Leo (2003) describes how universities "striving to improve their reputations are willing to extend unprecedented amounts of financial capital in order to entice scholars whose affiliation with their university may increase their reputation... The star scholar's affiliation confers value on the institution by virtue of the prestige associated with his or her name... The hiring of star professors becomes a marketing campaign conducted for short-term visibility" (2-3). While hiring may be limited to universities, in academia.edu anyone can "follow" star scholars.

In addition to institutional affiliations and the affinities that they afford, the "followed" and their "followers" can display their photo, research interests, CV, public talks, books, papers, status updates, and their "relationships," which are established through the act of "following" the work of others. These supposedly non-institutionalized affiliations offer a black market of veneered self-rankings and the remote possibility that one might take on and affinity-based status of those whom one "follows," and thus generate a "following" made up of other amateurs. This highly professionalized and disciplined display involves what Luke (1999) described as the drawing of comparisons "between oneself and others to build these disciplined nomenklaturas, in turn, leads to regimes of classification to appraise relative visibility, professional reputation, or academic impact..." (358). Like the art auction, academia.edu is a "sublime sphere of status" offering the opportunity to live out a fantasy of "links" to academic nobility, to enter into the community of the privileged, to create an affinity between oneself and elite intellectuals whom one follows obsessively, extracting status through the assertion of parity.

In the same way that Baudrillard's art lover displays obsession with the pedigree and genealogy of artists' 
paintings, affiliation collector Josh Dever's (2011) blog, “The Philosophy Family Tree," displays obsession with the pedigree and genealogy of academics' curriculum vitae. While certainly it is enriching when attempting to know someone to learn what ideas influenced them, what their favorite books might have been, or what they were reading at a particular point in time, these personal communications are absent from Dever's project, which implies that the value of an author's work, like the value of an artist's painting, cannot be determined without authentication of its origins. Everyone must be known, taken account of, and positioned within the hierarchy of signs in order to assign author-value. With the feverishness of a nineteenth century colonial missionary, Dever sponsors "orphans of the week" in public appeals for contributions to his attempt to trace the affinities of philosophers without parents: "Black was influenced by Russell, Wittgenstein, Moore, and Ramsey while an undergraduate at Cambridge, but he received a doctorate from the University of London in 1939, so I'd like to find his advisor for that degree to use for his parentage. Anyone know anything useful?” (Dever 2011: Thursday, July 21, 2005). Like the academic conference and academia.edu, this exchange of signs has little to do with the exchange of knowledge and more to do with securing the boundaries of the status order, which Dever takes pleasure in governing.

While they are populated by status displays, it also may be that spaces such as academia.edu represent attempts to find a personal connection in a career dominated by institutional affiliation and leaving little opportunity to know an author independent of their affiliation. Academic conference hallways are crowded with badge gazers who do not look you in the eye, but look you in name badge, awkwardly squinting to see the institutional affiliation listed below your name before calculating your value. One such badge gazer wasted nearly a minute in conversation with me before realizing that UTA was the University of Texas at Arlington, not the University of Texas at Austin, and abruptly turning away mid-sentence, anxious that time might be wasted interacting with an individual from whom nothing could be gained. This behavior curiously reveals a lack of trust in one's own judgment and the value of one's own thought. "Victims of their elite status, these deserving, but miraculously lucky, 'survivors', present a curious mixture of arrogance and inadequacy which immediately strikes the foreign observer..." (Bourdieu 1984b: 100).

To interact according to affiliation rather than according to one's own judgment reveals a fear of appearing as though one has not been properly refined and does not know the rules. Caesar (2000) recounts his observation of a transgression of unspoken conference norms by an outsider, noting that conference attendees "are expected to stay respectful about the dynamics of what the badge of each one proclaims: institutional affiliation... Does it matter in some specific way where the protestor was from? My feeling is that it does. But in any case the scandal is that it didn't appear to matter to him" (60). Status seekers avoid affinity with such persons, as though their ranking might be contagious. Urgo (1999) tells of one such avoidance: "We were at a conference dinner and the conversation turned to complaints about the burdens of graduate instruction. I turned to this person and made a polite remark of affinity since neither of our institutions had a graduate program. The look on his face at the prospect of being in my boat could have stopped a clock" (9). Moments like this point to the personal stress involved in publically upholding the myth of merit upon which the affiliation function relies. The result is often a self-fulfilling prophecy: it is difficult to make dinner conversation with someone whose mind is consumed with mastering a new place setting. Under these sorts of pressures, many academics wrongly internalize their "rank" as an accurate measure of their value, even as they attempt to demonstrate the manners of the highly-ranked, who, already possessing it, voice disregard for the value of such measures. It is a lot for one mind to manage. As Luke (1999) notes: "Many will dismiss such rankings in public as philistine... in private they admit such rankings are used to generate real differences and allocate various rewards. In them, dark tales of scholarly self-affirmation create and then (re)valorize professional notions of significance out of signs of apparent status" (356).

Away from conference dinner tables, the anonymity of the job blogs provides an opportunity for the unrefined "learn the secrets success" of without the risk of revealing one's status as a lowly-ranked status-gazer: anyone who has to ask does not have it. Even in their anonymity, the job blogs exhibit the "exalting and continual obsession of all other amateurs..." and a fixation with how the affiliation will be valued in the job market:

\section{Anonymous said...}

I see no downside at all to publishing as a grad student, as long as the articles are well placed. In fact, if you are $\mathrm{PhD}$ from a non-Harvard/Princeton/Chicago/etc. program, you damn well better. I doubt the ND candidates would have a shot at a tenure track job without strong publications, no matter how good their work might be in some objective way. Look at this year and where the current ND candidates have published (from the dept. website; I know none of these people):

Cherry: AJPS, HPT

Church: JOP, HPT, Interpretations 
Cohen de Lara: Polis, Acta Politica

Thunder: AJPS, PS

I've read the Thunder AJPS piece and the Church JOP piece; both are excellent. I just don't believe for a second someone with a record like Church, for example, would just now be getting a visiting position if they were coming from Princeton. Or that Thunder would be unemployed if he came from Harvard.

In short, if you are a strong theorist from a good program that can't place people based on adviser networks and reputation alone, PUBLISH. If you don't you won't get work, since your file won't get reviewed and your writing samples won't be read without that outside credibility. The placements this year seem to support that advice, by the way. Lots of jobs went to PhD's from non-elite programs with decent publications.

7:01 PM, May 01, 2008

Anonymous said...

What I don't understand is that ND is considered a top ten program (or at least was in the most recent rankings)...

9:21 AM, May 02, 2008

Anonymous said...

As many others have said, it's hard to rank 10 as there are many programs that have strengths. Some were ranked some weren't, but theorists recognize - I think - that ND is a good place.

Many of the people who got jobs had no pubs, so it may help but it certainly isn't the magic wand people are pretending. The market is more bingo-like than suggested. 10:48 AM, May 02, 2008

\section{Anonymous said...}

but were any of those who got jobs with no pubs coming from non-top 5 programs? that is the operative question, is it not?

11:51 AM, May 02, 2008

Anonymous said...

The wiki is down, but the answer is yes many people from non-top 5 places got jobs with zero refereed articles. About 129 of them were from Minnesota.

12:26 PM, May 02, 2008

Anonymous said...

...If you want to define elite as top 3 or 5 , then okay, but that seems extremely narrow. If you say top ten or top 15, then no there are only three or so jobs going to those people.

Minnesota is elite, ND is elite, Cornell is probably elite.

The TT hires from the past few years show a clear pattern: go to a top 10 program, unless you have non-academic options that you could fall back on if you don't get a job... 6:34 PM, May 02, 2008

\section{Anonymous said...}

If all those places count as elite programs, then virtually everyone who got a job is from an elite school and the purported distinction (between needing pubs if you aren't coming from a top school and not if you are) is meaningless. [Cornell is elite? Really??] 6:53 PM, May 02, 2008

(Political Theory and Public Law Job Market Blog, 2011).

This dialogue between "no ones" is dominated by an uncertainty concerning how to determine value in order to participate in the auction and a search for clues to how one can most effectively demonstrate affinity with valued institutions. The focus returns again and again to how one determines which characteristics are most valued: how 
much is my canvas worth? How much are my peers' canvasses worth compared to mine? Which canvases are going at the highest rate?

Anonymity also provides an outlet for those who yearn to exercise their bragging rights without appearing overexcited about their elite status; only a no one would insist that they are a someone. While those who have collected prestigious affiliations may harbor an urge to display their status, this urge must be suppressed in order to sustain the myth of affiliation as a reward for merit, rather than appearing to be something pursued for its sign value. One learns to replace the obvious "I went to Harvard" with the more casual "This scone reminds me of a café in Cambridge. I used to study there because they were open until 2 AM." The merit alibi relies upon the display of nonchalance about one's affiliation, which everyone must assume that they have earned by virtue of some special intrinsic quality. This assumption holds as long as those who have not yet achieved "it" sustain the following. Self-promotion is considered gauche by status insiders because Harvard's prestige is earned at the discretion of those who do not posses it, but who nevertheless subscribe to its reputation with little or no actual knowledge about what goes on there. "I went to Harvard" would be an admission that one's status is dependent upon the admiration of the lower-ranked; lifestyle indicators associated with Harvard casually inserted into conversation put the onus on the admirer to ask: "Did you go to Harvard?" Thus, Harvard's prestige appears to be merited, as evidenced by widespread admiration.

Only Harvard stands to gain from the energies of those trying to achieve affinity with Harvard. The lowerranked have nothing to lose in criticizing the politics of affiliation prestige -- withholding criticism is not going to secure a lowly-ranked Ph.D. an affiliation with Harvard -- and yet it is the lower-ranked who spend their time fortifying this prestige as they contribute to the "following." It is therefore troubling that in the time spent "following pedigree" in pursuit of "prestigious" affiliation one could write multiple award-worthy entries for the Telos essay competition and yet never be considered as an author. This is not to fault those who engage in the practices of status display; I myself have done the same many times. It may be a matter of survival, but it also is a devaluation of the self that makes it difficult to write a contribution to dialogue about possible alternatives to the treatment of each other as commodities.

\section{| The Anxieties of Academic Affiliation and Status Disqualification}

I can easily imagine that the letterhead, which was a delightful surprise, could significantly reinforce the possible effect of the document. The complete uncertainty about what the next day, even the next hour, may bring has dominated my life for weeks now... PS Please forgive the painfully complete signature: it is officially required. - Walter Benjamin to Theodore Adorno, August 2, 1940

The necessity for affiliation is a more serious problem than the academic theatre of status might suggest. There is more at stake here than award-winning essays and internationally recognized institutions, making it all the more troubling that the opportunity to write in dialogue with an intellectual community is now so far removed from individual expression and so deeply embedded in affiliation. The somewhat celebratory tone of the display of fashionable affiliations by untenured academics betrays deeply held anxieties about their ability to maintain attachment status. These anxieties are not unwarranted; more often than not, the academic career does indeed depend upon prefacing one's individual contribution with status displays accumulated through adherence to a valorized manner of ascribing validity to the affiliation function.

No junior academic who hopes to achieve tenure, including the author of this essay, desires to be unaffiliated - a position that would render their potential contributions valueless and possibly result in permanent status disqualification, which occurs when one does not obtain institutional affiliation within the first few years after earning a Ph.D. The ideal academic career path - presenting draft chapters of one's dissertation at (expensive) conferences, being nominated by one's advisor for a "best student conference paper" award, winning an essay contest, publishing a peer-reviewed paper in a highly-ranked journal, entering the job market as an "ABD," defending one's dissertation in May in order to take up affiliation as an Assistant Professor in August, receiving a course release in order to have time to publish one's dissertation work, securing grant funding, and applying for early tenure- is also the normal career path and deviations, such as a year of unemployment, reduce one's academic capital. There is no time for deviation. As Bourdieu (1984a) explains,

"the structure of the field is perceived by the agents in the form of an ideal career - from the Ecole Normale to the Institute, passing through the stages of assistant lecturer and then a chair at the Sorbonne - against which all other trajectories are obviously measured... It is this very order which threatens the celeritas of those who want to 'cut corners' (for example, by 
importing into the university field properties or powers acquired on other terrains), as against gravitas, of reliability (in writing a thesis, for instance) and which is really the most authentic proof of obsequium, unconditional respect for the fundamental principles of the established order" (87).

Just as Lavin's hire at Virginia Tech, which was portrayed as success in spite of the status order, caused a sense of disorder, to depart from the normal career path and also succeed would be a tacit challenge to the principles of the established order, which ensures that only the normal knowledge lifestyle is legitimated and sought after.

When Marc Bousquet (2002) observed that "degree holding no longer represents control over who may practice. Indeed, the inescapable observation must be this: under casualization, degree holding increasingly represents a disqualification from practice" (87) he pointed to the void that one enters between the Ph.D. program (at which point one possesses affiliation) and the job market for those who do not secure a new affiliation before they graduate. This void not only disqualifies one from teaching positions associated with their Ph.D. program, as Bousquet observes, but also often disqualifies one as a candidate for tenure-track jobs. Any distance from affiliation for any period of time brands one as unfit to return. As anonymous 12:48 PM relayed, "This, by the way, is another reason why attending a 'top' program is important; since the opposite signal is being sent if you *don't* get admitted to one of those programs" (Political Theory and Public Law Job Market Blog 2009). The same signals are embedded in one’s first academic job, which Urgo (1999) describes as a defining moment: "The job one lands is definitional... Far from filling a position, the candidate is filled by it... like paternity, there is little one can do about it once it's done. One is a loose fish for only so long after the Ph.D., then it's either get caught somewhere or disappear into the icy waters of independent scholarship" (19). Icy because non-affiliation is more often than not received as a signal that something was wrong with you: why would we associate with, let alone hire, someone whom our peers did not value? This is an amateur's evaluation of an artist, relying on the suggested value of the opening bid rather than trusting one's own judgment of value.

As they participate in this circuitry of value, academics pursuing the normal path of the academic career become complicit in the casualization of the university. Faculty members, encouraged by the university to accumulate prestigious grants, earn teaching "buy out." The grant-maker, who typically funds only affiliated individuals who posses prestigious letterhead (Caesar 1992), pays for someone else to teach in the vacated classrooms while the grant recipient pursues -- and contributes affiliation value to -- the grant-maker's objectives. This exchange allows faculty members to collect affiliation with prestigious foundations without abandoning their affiliation with the university, while the university capitalizes on the sign value that they extract when their faculty members achieve more value.

The casualization of academic labor by the university is at least partially explained by this casualization of the university by academic labor. Entire careers are structured by those who act as placeholders for an elite cohort of affiliation collectors. These sublet affiliations secure a primary affiliation (a tenure track job) for faculty members while they accumulate more affiliation power (a post-doc at Stanford, a visiting position at Harvard, monetary recognition by a prestigious foundation endowed by high society philanthropists), which they can later trade in for affiliation at a more prestigious university. For many, the tenure track job has become a temporary input in the curriculum vitae of a whole class of status climbers. While those who already possess affiliation are empowered to be "absent" from universities seeking to increase their rank via travelling academics who "take a break" from their jobs in order to achieve affinity with higher-ranked universities and potential donors to the university endowment, those still seeking permanent affiliation sublet the vacated affiliation status as "visitors" in the hopes that they might delay the disqualification that results from "a break" in affiliation. This practice borders on an elaborate arbitrage scheme involving affiliation arbitragers guaranteed a status gain - which is achieved by holding two risk-free positions at once -- while others bear the risks of absent graduate supervisors, courses without instructors, and lives placed on hold by temporary contracts.

Given the limited amount of time that one has to successfully navigate this normal path, it is unsurprising that the anxiety anonymously expressed by academics seeking affiliation and letterhead is characterized by painful uncertainty.

HEREWEGOAGAIN: Soooooo, anyone ready to jump off the building yet? Oct 21, 2010

RERUN: I'm still in the stress vomiting stage. But stay tuned Oct 21, 2010

ABC123: Yeah I'm on edge. Oct 21, 2010

YEP: ugh, getting there. Oct 25, 2010 
HEREWEGOAGAIN: I am really starting to freak out. I know it is early (that's what I keep telling myself at least), but I am going nuts. Oct 25,2010

RERUN: I assume from your pseudonym that this is (at least) your second time on the market? It's my second round, and I am so much more stressed out than last year. I was pretty confident last year, but as time went on and nothing I began applying for jobs that were't really realistic given my life constraints, and I wound up turning down my only offer. THis year I'm starting off completely crazed. Oct 25,2010

HEREWEGOAGAIN: Yep, this is my second year too. Pretty much the same thing happened to me last year...didn't hear anything at first, freaked out and starting applying tp places that didn't make any sense for me, turned down a couple of interviews. Did an on campus interview at a place I LOVED but didn't get the offer. This year I am a total mess. The fact that I have no hits so far is not helping matters any. Oct 26, 2010

RANT: Fuck inside hires. That is all. Oct 26, 2010...

GUEST: If applying for a job seems so stressful, how will you cope with the pressure-filled years of working toward tenure, developing course preparations, negotiating through department culture, and so forth? Oct 26, 2010

HEREWEGOAGAIN: I tried to make that same point last year and got my head torn off by a whole bunch of people on here. I don't think it is a bad point; this is a stressful line of work all the way around. I am actually in a TT position right now (looking to move to a place that better fits my talents), and I can say that "looking for job" stress and "on the job" stress are pretty different. I am not saying that one is better or worse than the other, but just because you find the job hunt extremely stressful doesn't mean you will be overwhelmed by the job. Apples and oranges. Oct 26, 2010

RERUN: Applying isn't stressful. Not having a job is stressful. Last year I couldn't understand what everyone was all worked up about until the end of November when I had no bites yet. And if you knew anything about me and my life beyond what's posted on this board, I doubt you'd be so patronizing. Oct 26, 2010

TICK, TICK, TICK: my rant of the day: almost everyone on the market in my dept has now heard from somewhere (or several places) and i have not heard anything yet! i know it is early etc but it is making me panicky. this is my THIRD (and last?) time so i need something to come through! Oct 26, 2010

SUPPORT: it's really early. just look at the long list of schools hiring on the wiki, and the short list that has contacted candidates!!! Oct 26,2010

OBSERVER: I'd feel stressed too if I were the only one in my comparison group to not have a glimmer of interest shown yet... Oct 26, 2010.

Soc. Rumor Mill 2010-2011 (2011)

The subjectivities projected in these noms de plum only reinforce outsider status as something to be avoided. To be unaffiliated is described in terms of expiration dates, rants against insiders, observer rather than participant status, the need for a support group, and a remedial track of repetition. This characterization of outsider status reveals how, in the process of getting inside, one gradually pushes aside alternative subjectivities, such "critic." The author function manifests in the academic profession not only in its construction of the boundary of legitimate knowledge, but, as this boundary is lived out in the careers of academics, it also manifests in the production of this affiliation subjectivity. It matters, Jacoby (2000) argues, "whether intellectuals obsess about a single editor who judges their work or three 'referees,' ten colleagues, several committees, and various deans. Universities encourage a definite intellectual form. They do not shoot, they simply do not hire those who are unable or unwilling to fit in" (232).

Perhaps due to job market anxiety or perhaps due to the relationship between one's success and one's internalization of "normal," even in an anonymous forum anxiety about the job market is reframed as an inability to cope: "If applying for a job seems so stressful, how will you cope with the pressure-filled years of working toward tenure, developing course preparations, negotiating through department culture, and so forth?" The suggestion that anyone of merit should be able to cope is also the reinforcement of the myth that it is not academic life that is flawed, but the individuals who "cannot cope" with it (Nickel and Eikenberry 2006). In fact, many successful academics are not coping well at all, but feel pressured, whether by the pressures for affiliation or by anonymous "guests" on blogs, to project the appearance that everything is okay (Nickel 2008).

These scenes of desperation reveal a growing awareness that one's success in academia has little to do with one's effort or talent, but instead involves a series of wagers in which one must balance the risk of a poorly-made investment with the possibility of hitting the affiliation jackpot. It probably is true that not every Ph.D. on the job 
market "merits" employment by an academic institution and not everyone who seeks one will secure an academic position. However, the boundaries constituted by the affiliation function will exclude many who are capable of making significant contributions and include many who are capable only of making significant displays of status on their way to the next rung in the status hierarchy. When "public universities have cut costs largely by freezing hiring for vacant staff and adjunct faculty positions, deferring maintenance costs, and collapsing courses to create fewer, but larger course sections..." (Kelderman 2009) a gap in employment does not necessarily reflect the abilities of academics who do not "cope" well or who do not secure one of the few jobs available. Surely someone who does not secure an institutional appointment in these circumstances should not be rendered a "no one" and denied the opportunity to be considered in the judgment of "creative, fresh, and original contributions in the area of politics, philosophy, critical theory, theology, culture, and the arts."

\section{Conclusion}

At a time when successful participation in society could not be divorced from one's pedigree, Charles Dickens' "man from Somewhere" was forced to conceal his affiliations in order to discern the character of those with whom he hoped to enter into personal, rather than status-based, relations, resulting in great confusion and intrigue. "We are all very much interested in the man from Somewhere... Deeply interested! Quite excited! Dramatic! Man from Nowhere, perhaps!" In academic society today, it seems that we are similarly incapable of understanding and interacting with an individual without first having knowledge of their institutional affiliation and its rank in the status order; one's value cannot be discerned without letterhead, name badge, sweatshirt, or academia.edu family tree. Without these signs, affiliation malfunctions in the management of legitimate knowledge. This is problematic because the request for an author's affiliation preserves the practice of legitimating knowledge according to existing value relations. Knowledge circulating in this way inhibits rather than facilitates the emergence of "creative, fresh, and original contributions in the area of politics, philosophy, critical theory, theology, culture, and the arts."

This is not to argue against institutional affiliation or against the universities that provide it. Institutional affiliation is valuable; it provides mentors, colleagues, research resources, students, community, spontaneous dialogue, tenure, and, often, just a needed distraction. Universities are important institutions and many of the norms that historically they have guarded are essential elements of any society that hopes to cultivate critical thought. These valuable relations are at risk when the "affiliation necessity" acts as a qualifying characteristic of the author and as an ordering principle of a "normal" academic career that is increasingly dominated by the "production necessity." Much of the activity that junior academics engage in serves no purpose other than to achieve author status and contribute to the production of affiliation-value, distracting them from the real opportunities that universities provide, which have nothing to do with the ranking of one's letterhead.

Concern with the decline in the well-being of a cohort of recent Ph.D.s may seem maudlin. One could make the very reasonable claim that we are faced with more pressing problems than the working conditions of academics. Yet, these pressing problems are more than ever knowledge problem reinforced by the affiliation function. The requirement for "internationally recognized" institutional affiliation and the associated "opportunity to be published in one of the leading international interdisciplinary journals," exemplify an era dominated by knowledge that is given value via the author according to the symbolic value of the institutions with which it is affiliated. The affiliation function governs the possession of authority; it governs the determination of merit; it governs the boundaries of legitimate speech; it governs the placement of university logos behind "experts" invited by the media to identify the root of a crisis; it governs the distribution of resources dedicated to "transformative practices." Knowledge governs and affiliation is governing knowledge production. It therefore matters, or, at the least, it is telling of a more widespread problem, that Telos, a journal celebrated for its iconoclasm, has collapsed critique and affiliation in a competition that would exclude its founding editor and many of the now "prestigious" authors whose criticisms he published. 


\section{References}

Academia.edu. 2011. http://harvard.academia.edu/Departments/ Kennedy_School_of_Government. Retrieved February 16, 2011; the page reflected in the screen capture has since been modified.

Agger, Ben. 1989. Reading Science: A Literary, Political, and Sociological Analysis. Dix Hills, New York: General Hall, Inc.

----.. 1990. The Decline of Discourse: Reading, Writing and Resistance in Postmodern Capitalism. New York: The Falmer Press.

Baudrillard, Jean 1981. For a Critique of the Political Economy of the Sign. St. Louis, Mo.: Telos Press.

Bawarshi, Anis 2000. “The Genre Function.” College English 62 (3): 335-360.

Bourdieu, Pierre. 1984a. Distinction: A Social Critique of the Judgement of Taste. Translated by Richard Nice. Cambridge, MA: Harvard University Press.

-.---. 1984b. Homo Academicus. Translated by Peter Collier. Stanford, CA: Stanford University Press.

Bousquet, Marc. 2002. "The Waste Product of Graduate Education: Toward a Dictatorship of the Flexible." Social Text 70 (1): 81-104.

Caesar, Terry. 2000. Traveling through the Boondocks: In and Out of Academic Hierarchy. Albany: State University of New York Press.

-.---. 1992. Conspiring with Forms: Life in Academic Texts. Athens and London: University of Georgia Press.

Crampton, Jeremy W. 2003. The Political Mapping of Cyberspace. Chicago: The University of Chicago Press.

Dever, Josh 2011. The Philosophy Family Tree. http://philtree. blogspot.com. Retrieved February 16, 2011.

Di Leo, Jeffery R. 2003. “Understanding Affiliation.” In Affiliations: Identity in Academic Culture. Edited by Jeffery R. Di Leo. Lincoln: University of Nebraska Press: 1-16.

Fish, Stanley 1989. Doing What Comes Naturally: Change, Rhetoric, and the Practice of Theory in Literary and Legal Studies. Durham and London: Duke University Press.

Foucault, Michel 1980. Power/Knowledge: Selected Interviews and Other Writings 1972-1977. Edited and translated by Collin Gordon, translated by Leo Marshal, John Mepham, and Kate Sopher. New York: Pantheon Books.

-.---. 1998. "What is an Author?" In Aesthetics, Method, and Epistemology. Edited by James D. Faubion. New York: The New Press: 205-222.

Gouldner, Alvin 1970. The Coming Crisis of Western Sociology. New York: Basic Books, Inc.
INCITE! Women of Color Against Violence, ed. 2007. The Revolution Will not be Funded: Beyond the Non-profit Industrial Complex. Cambridge, MA: South End Press.

Jacoby, Russell 2000. The Last Intellectuals: American Culture in the Age of Academe. New York: Basic Books.

Kelderman, Eric 2009. "Land-Grant Universities Consider Restructuring to Cope With Expected Shortfalls." Chronicle of Higher Education, November 12, 2009.

Lefebvre, Henri. 1991. The Production of Space. Translated by Donald Nicholson-Smith. Oxford: Blackwell.

Luke, Timothy W. 1999. "The Discipline as Disciplinary Normalization: Networks of Research." New Political Science $21(3): 345-63$.

Marx, Karl. 1978. "Economic and Philosophic Manuscripts of 1844." In The Marx-Engels Reader. Edited by Robert C. Tucker. New York, NY: W.W. Norton and Company: 66-125.

McGurl, Mark. 2009 The Program Era: Postwar Fiction and the Rise of Creative Writing. Cambridge and London: Harvard University Press.

Nickel, Patricia Mooney. 2008. “There is an Unknown on Campus: From Normative to Performative Violence in Academia." In Tragedy and Terror at Virginia Tech: There Is a Gunman on Campus. Edited by Ben Agger and Tim Luke. Lanham: Rowman \& Littlefield: 161-186.

Nickel, Patricia Mooney and Angela M. Eikenberry 2006. "Beyond Public vs. Private Management: The Transformative Potential of Democratic Feminist Management." Administrative Theory \& Praxis 28(3): 359-380.

Political Theory and Public Law Job Market Blog. "2009-10 Prospective Graduate Students Post \# 1" http://politicaltheoryrumormill.blogspot.com/2009/07/2009-10-prospective-graduate-students.html. Retrieved January 25, 2011.

...... "Political theory junior job market thread 5, 2007-08." https://www.blogger.com/comment.g?blogID $=21008160 \&$ postID $=85098782101250436$. Retrieved January 25, 2011.

Rousseau, Jean-Jacques 1964. The First and Second Discourses. Edited by Roger D. Masters. Translated by Roger D. Masters and Judith R. Masters. New York: St. Martin's Press.

Soc. Rumor Mill 2010-2011 2011. “RANTS!!!” http:// socjob2010.proboards.com/index.cgi ?board=talk\&action $=$ display\&thread $=431$. Retrieved January 25, 2011.

Telos Press 2010. TELOS Essay Prize Competition. http://www. telospress.com. Retrieved January 2, 2010.

Urgo, Joseph 1999. "The Affiliation Blues." symploke 7 (1-2): 7-20. 
Waldo, Dwight. 1948. The Administrative State: A Study of the Political Theory of American Public Administration. New York: The Ronald Press Company.

Weber, Max. 1975. “The Distribution of Power within Political Community: Class, Status, Party." From Max Weber: Essays in Sociology. Edited and translated by H. H. Gerth and C. Wright Mills. New York: Oxford University Press: 180-195. 
